\title{
Os sites dos ministérios de relações exteriores no mundo e a História ${ }^{1}$
}

\section{DENIS ROLLAND*}

As instituições possuem memória. Memória que possui uma relação muito variável com a História.

Há uma nova fonte, ainda pouco estudada, em expansão extremamente rápida e que fez surgir alguns poucos estudos críticos: a Internet. Ora, a Internet propõe a história. E a história em qualidade e quantidade bastante variáveis.

O problema é que o espírito crítico do leitor não funciona da mesma forma lidando com a Internet ou com livros e revistas: ao ler a revista de grande público Historia, o leitor prevenido sabe que não está lendo uma revista científica como Annales, Genèse ou Matériaux pour l'histoire de notre temps. Na Internet, o nível de credibilidade científica é freqüentemente desconhecido. Ao contrário do que acontece com a produção impressa, para a qual os instrumentos de diferenciação são conhecidos (bibliografias, recensões críticas, reputação científica,...), na "rede” existem poucos meios de se avaliar a qualidade da oferta proposta; e as sitografias não são nem numerosas nem confiáveis. Existe outro fator agravante: a virtualidade da informação conduz a uma falta de distanciamento. Devido a um contato mais distanciado com a fonte, também mais diversificada, a informação obtida na tela é $a$ priori avaliada e utilizada por alunos, estudantes, e jovens pesquisadores, com ainda menos filtros críticos do que os usados para a informação impressa. De uma certa maneira, a mágica da acessibilidade, associada à juventude do meio de informação, reduz o olhar crítico potencial.

Existe um exemplo particularmente esclarecedor da vastíssima variedade qualitativa dessa confusão informativa, concebida com parâmetros e objetivos muito diversos, mas raramente anódinos: a referência à História. Em todo o planeta, os ministérios das relações exteriores equiparam-se de sites na Internet concebidos, ao mesmo tempo como instrumentos práticos e como vitrines. A experiência prova que eles são doravante utilizados de boa vontade como fonte de informação e de documentação por estudantes e interessados em história ou relações internacionais. Tais ministérios - estruturas de Estado antigas, bastante visíveis do exterior por definição, e conscientes do papel que possuem na difusão de uma imagem nacional 
- são atores de relações internacionais, dentre outros, e possuem uma forte ligação com a história do país via história das relações diplomáticas (durante muito tempo confundidas com a história das relações internacionais).

Nem todos os Estados são providos de sites ministeriais: muitos ministérios das relações exteriores de países pouco desenvolvidos não o possuem, muitas vezes devido à pobreza, como a maior parte dos países africanos, Paraguai ou Cuba. Contudo ao navegar pelos sites existentes dos ministérios encarregados das relações internacionais uma constatação se impõe: nos países desenvolvidos ou em processo de industrialização, a referência à história, quando existente, não está ligada à estrutura ministerial, mas aparenta ser mais ligada à vontade dos seus responsáveis de não mostrar, ou mostrar em parte a história nacional. A construção de um site de Internet é geralmente o resultado de um caderno de encargos precisos. Assim, a decisão de recorrer ou não à história parece ter sentido: ela tem a ver principalmente com a representação que os governantes dos países desejam mostrar de si próprios, a uma certa concepção ou escala da potência nacional ${ }^{2}$.

A referência atrelada à história destas diferentes instituições é muito ampla, variando entre dois pólos: os ministérios que construíram seus sites sem história e aqueles para os quais a história é essencial.

Há sites governamentais que não possuem história, os sites dos ministérios das relações exteriores espanhol e argentino. Há outros que atribuem, ao contrário, grande importância à história, os ministérios francês e brasileiro. Sem dúvida, há povos que se interessam menos pela história (e pela sua história) que outros. Mas existe uma norma ou um ideal a atingir que deva ser partilhado entre os ministérios homólogos de um mundo globalizado? Os exemplos francês e brasileiro, muito voltados para seu passado por razões sensivelmente diferentes, devem ser considerados como situações exemplo de referência ou como extremos ${ }^{3}$ ?

No pântano entre estas duas opções, existem gradações. Dentre os ministérios das relações exteriores que, por sua apresentação na grande rede, não tem a história como tema, sem necessariamente negligenciá-la, o britânico Foreign and Commonwealth Office e, ainda que menos reservado, a Farnesina, o ministério italiano de relações exteriores; e, dentre os que fornecem elementos descontínuos, o Département Fédéral des Affaires Étrangères (DFAE) da Confederação Helvética. Dentre aqueles que fornecem elementos de informação detalhados e úteis, sem no entanto desenvolver amplamente sua história diplomática, o State Department (EUA), o MID (Rússia), o Palácio das Necessidades (Portugal), o ministério das relações exteriores da República Popular da China e, dentro de uma medida de abordagem linear reduzida, o ministério belga de relações exteriores. O exame detalhado de 14 sites, simplesmente classificados em função da ausência ou presença de entrada(s) histórica(s), terá como objetivo avaliar os pesos da memória nacional e/ou institucional na redação de uma entrada implicando particularmente a imagem que um Estado deseja fornecer de si mesmo. 


\section{Relações exteriores: amnésia histórica total ou parcial}

Alguns sites não possuem história, ou muito pouca.

O pouco interesse de certos países em dar uma visão retrospectiva de suas relações internacionais é uma explicação um pouco simplista, mesmo se completada pela utilização de meios financeiros exagerados na construção de outros sites eventualmente menos importantes. De fato, parece que a difícil administração de um passado recente tem podido influenciar a decisão dos promotores do site. Em outros termos, como explicar, em um quadro institucional, um passado recente gerador de conflitos, violências e feridas, onde os atores estão, às vezes, ainda vivos e, talvez, no exercício da função?

Tal é, sem dúvida, a dificuldade não contornada que contribui para explicar porque nem Espanha, nem Argentina sejam dotadas de entrada histórica em seus sites ministeriais, já que os dois países gostam de celebrar a grandeza de seu passado, o império de um, as lembranças do desenvolvimento econômico ou certos ícones políticos de outro.

Para a Espanha, o franquismo é um passado ainda fervente. Não precisa ser um grande historiador para perceber tal fato. Mas deve-se acrescentar a este dado geral a idéia de que a transição democrática brilhantemente conseguida pelo país repousa sobre uma ausência deliberada e quase total de vontade de "depuração" em nome da paz e tranqüilidade civis. A maior parte dos funcionários do Ministerio de Asuntos Exteriores da época do franquismo continuam em seus postos. Como apresentar, nestas condições, em termos científicos e não obstante oficiais, a história da Guerra Civil, da cruzada franquista, do franquismo de guerra e da longa ditadura que se prolongou no século XX? Sob diversos pontos de vista, não escrever a história quando não necessário facilita a gestão do presente. Então, das 13 entradas da página de abertura, nenhuma apresenta a história (www.mae.es) ${ }^{4}$.

Na Argentina, a situação pode a priori ser apreendida com hipóteses similares (mesmo que os meios financeiros possam ter pesado mais). A Cancillería não possui história on line. Entretanto, o país gosta de procurar, em um passado nem tão distante, as manifestações de um crescimento rápido e de uma possível potência como as do Hemisfério Norte. Sem história no site do ministério, não há apresentação das diferentes gestões das relações exteriores pelos grandes partidos políticos nacionais, nem mudança de regime a apresentar e, portanto, não há administração do recente, difícil e mortífero passado militar; também não há utilidade em administrar a política externa Argentina, propositalmente errática diante dos Estados Unidos. Se o historiador não sabe exatamente as razões que conduziram a esta ausência de história, pode compreender as dificuldades que levaram a excluir a história, talvez as vantagens que o ministério pode ter não abordando uma questão delicada em um site, na realidade pouco desenvolvido ${ }^{5}$ (www.mrecic.gov.ar). 
Estes dois sites, mais detalhadamente no caso espanhol (13 entradas contra 4), são sites exclusivamente funcionais e práticos, sem enraizamento no passado.

Existem casos diferentes: um ministério que, sobre uma trama histórica muito resumida, omite um quarto de século de sua história; um outro cujo relato histórico não ultrapassa a última mudança de regime...

A Itália apresenta muito pouco da sua história institucional no site de seu Ministério das Relações Exteriores, a Farnesina (www.esteri.it). Um pouco quando trata dos edifícios do ministério (www.esteri.it/lafernesina/luoghi/index.htm), um pouco na entrada "Servizio Storico", mas somente para relatar a história dos arquivos do ministério em alguns parágrafos (www.esteri.it/archivi/servsto/archivsto/ archiv1.htm)... Nada que mencione os anos de fascismo, Mussolini, ou qualquer ministro das relações exteriores do período, mesmo que, por exemplo, o imponente edifício principal do ministério no Foro Italico, não seja estranho à política arquitetônica do fascismo. Parece que o passado não deve ser assumido ou não é julgado apresentável ao exterior (apesar dos evidentes traços de continuidade na sociedade contemporânea) ou enfim, simplesmente não é necessário.

Esta seletividade não é exclusividade dos regimes democráticos frente ao seu passado autoritário: a autocrática China comunista tem o mesmo reflexo de desconfiança e ocultação de seu passado "diferente".

A versão inglesa do site do Ministry of Foreign Affairs of the People’s Republic of China consagra uma parte modesta de sua arquitetura à história (www.fmprc.gov.cn/eng). Somente uma das 34 entradas é efetivamente consagrada à "Diplomatic History" (www.fmprc.gov.cn/eng/c698.html). Mas, por trás desta entrada única, 58 artigos varrem os temas e as áreas geográficas das relações exteriores de uma política externa chinesa muito voltada às pequenas sínteses do tipo "The Long-term Stable Constructive Partnership Between China and the European Union" 6 , "Establishment of Sino French Diplomatic Relations"7 (www.fmprc.gov.cn/eng/5689.html), “China and Brazil” (www.fmprc.gov.cn/eng/ 4320.html)... Todavia, e compreensivelmente, esta história diplomática da China é estritamente limitada à era comunista: a China imperial ou republicana antes de Mao não possui qualquer espaço nesta representação exterior da história chinesa. A amnésia histórica, parcial, repousa sobre uma seletividade política deliberada.

O caso do MOFA japonês é visivelmente diferente. O site em inglês do ministério japonês (www.mofa.go.jp) é também muito detalhado, com um sistema considerável de entrada dupla: 13 ou 55 entradas iniciais propostas sobre a página de abertura! Apesar disso, a história não é preocupação visível (nenhuma entrada se apresenta de uma só vez), nem uma preocupação global (nenhuma história geral do ministério). A partir das entradas "Postwar Issues” (www.mofa.go.jp/ policy/postwar/index.html) ou "Culture”, chega-se ao Bluebook (publicação de documentos diplomáticos dos últimos anos, acessível on line a partir de 1994), sem ter nada anterior. Procurando bem, a entrada "Regional Affairs" abriga diversas 
pequenas notas históricas sobre as relações exteriores do Japão (www.mofa.go.jp/ region), mas com profundidade histórica bem variável: se com o Oriente Médio, o autor faz voltar as relações à "rota da soja" (www.mofa.go.jp/region/middle_e/ relations/history.html), com os Estados Unidos, o histórico começa com a “derrota japonesa” (www.mofa.go.jp/region/n-am/us/relation.html) e, com a União Européia, somente em 1991 (www.mofa.go.jp/region/europe/eu/overview/history.html)...

\section{Relações exteriores: a memória necessária}

Existem países onde os ministérios de assuntos estrangeiros apresentam sua história na rede com moderação.

Existem aqueles que parecem fazer a história por necessidade (Suíça). Existem aqueles que parecem atribuir à história um local deliberadamente limitado, para tentar projetar a imagem do país para o futuro (Grã-Bretanha) e às vezes, também por falta de interesse, até passar sobre seus episódios complexos (Bélgica). Existem aqueles que atribuem à história um lugar mediano (Rússia, Portugal, Estados Unidos, Alemanha), gerando seu passado com mais ou menos evasivas, artifícios ou sorte.

Com base em seu site na Internet, o Département Fédéral des Affaires Étrangères (DFAE) da Confederação Helvética não é muito interessado pela história (www.dfae.admin.ch). Ele dá ao internauta longas páginas de história mas freqüentemente pela tangente de remeter a outros sites e somente para definir sua neutralidade (Comissão independente de especialistas denominada Comissão Bergier, “questões históricas” www.switzerland.taskforce.ch/W/W2/W2a/ al_fn.htm) ou para responder às críticas internacionais, principalmente em torno da Segunda Guerra Mundial (sub-entrada “Suisse-2ème Guerre Mondiale”. Assim, a história surge desde que seja indispensável à imagem nacional. Do contrário, não é necessária.

O Reino Unido procura dar de si mesmo uma imagem resolutamente voltada para o futuro. O site do Foreign and Commonwealth Office London é simbolicamente colocado sob a divisa "Creativity, innovation and quality" (www.fco.gov.uk). Relação de causa e efeito, parece, a história existe em doses homeopáticas, nas breves "History Notes"(www.fco.gov.uk/news/ keythemehome.asp?9) apresentando em algumas linhas os "FCO Historians", três séries de publicações históricas e alguns dados práticos, aos quais são adicionados novos artigos pontuais, todos consagrados ao século XX, a partir do "Britain's entry into the EC" ou "Nazi Gold” até "Women in Diplomacy”... Encontra-se também alguns elementos da história nacional por trás da fachada dos prédios do ministério www.fco.gov.uk/directory/dynpage.asp?Page=62 e www.fco.gov.uk/ directory/tour.asp). Isto não quer dizer que o ministério não se interessa por sua história, ao contrário: nenhum fuga da história nessa discrição, os trabalhos científicos 
publicados direta ou indiretamente sob a bandeira dos FCO Historians comprovam. Mas, dentro de sua auto-promoção pública, a história não é vista nem como determinante nem como prioritária.

O site do ministério belga das Relações Exteriores, do Comércio Exterior e da Cooperação para o Desenvolvimento (www.diplobel.org, www.diplobel.fgov.be) não esquece a história, mas também não se demora nela. É na entrada "Guide do Ministére” que encontramos um breve “Aperçu historique” (www.diplobel.org/ Ministry/gids\%20-\%20fr/2.htm). Às vezes redigido com destinação interna ("notre pays”), é dividido em quatro “períodos” cronológicos: 1830-1875, 1875-1914, entre duas guerras, após 1945. Ao menos a partir destes títulos, as duas guerras saíram da história do ministério: uma frase para citar "a neutralidade rompida” durante a Primeira Guerra Mundial, nada para a Segunda. A ocupação do território nacional durante a Primeira e Segunda Guerra Mundiais não explica grande coisa (a nacionalidade do invasor nunca é mencionada). Mas os governos no exílio existiram, trabalharam e, no interior do país, algumas instituições continuaram funcionando. Portanto, não há o que discutir: existem elementos de síndrome belga, como existe na França uma “síndrome de Vichy”, talvez menos importante, menos estudada e menos reconhecida que na França. E o site do ministério belga de relações exteriores é um reflexo deste aggiornamento não realizado da história institucional belga.

O site mexicano da Secretaría de Relaciones Exteriores (www.sre.gob.mx) confere um lugar importante à história ( $5^{\mathrm{a}}$ entrada sobre 14) (www.sre.gob.mx/ acerca/sre/historiasre.htm). Mas é uma longa exposição (21 páginas) linear apenas aparentemente. Atribui uma grande preponderância ao século XX (16 páginas) e, mais precisamente, aos últimos anos (8 páginas). Em um país que possui uma historiografia de grande qualidade e uma história das relações internacionais bem desenvolvida, a terminologia do corte cronológico, em seis períodos muito irregulares é um pouco surpreendente; e os cortes levam a pensar que o site não foi atualizado por uma revisão global, mas completado por acumulação. Após um "século XIX" bastante lógico, surge uma elíptica "alvorada do século XX" aonde espera-se a palavra Revolução. Segue, espantosamente, uma precoce (pela historiografia mexicana tradicional) “etapa pós-revolucionária” de 1917 a 1946, depois uma “etapa moderna” de 1946 a 2000. Mas a entrada se completa com um "fim do século XIX”, evocando as reformas de 1998, depois, um "novo milênio" que aborda, sem formulações explícitas, o fim da hegemonia política do Partido Revolucionário Institucional e, ao contrário, de maneira explícita, a alternância política com a chegada do Partido de Acción Nacional (PAN) ao poder. Esta última parte que, sozinha aparece na tela em negrito, insiste no fato de que "hoje podemos promover a imagem de um México democrático”. Em outras palavras, a Revolução é, se não engomada, pelo menos bastante explorada nesta representação do passado mexicano, muito voltada para o presente e deliberadamente aberta para o futuro. 
O site do ministério russo das relações exteriores ( $\mathrm{MID}^{8}$ ) é um site bastante completo (www.ln.mid.ru/website). Mas apenas na versão russa, as versões em inglês, francês, espanhol ou italiano, idênticas, sendo construídas muito pobremente, com apenas três entradas de atualidades. A menos que se considere que esta diferença não seja mais que o produto dos imperativos financeiros, deve-se interrogar sobre duas outras explicações possíveis e complementares: uma de cunho “nacionalista”, e outra consideração diferencial do acesso à informação entre o público nacional (ou russofônico) e o público estrangeiro (não-russofônico).

Em russo, portanto, a história não está ausente das dez entradas: o "serviço dos arquivos” apresenta um histórico global, uma cronologia dos ministros das relações exteriores e artigos de síntese sobre alguns temas (www.ln.mid.ru/website/ ns-arch.nsf). Três características distintas se apresentam. Por um lado, a história da Rússia dos czares é mais longamente desenvolvida (4/8) que aquela da URSS (3,5/8); e o site não insiste, dentro da entrada histórica, na política da nova Rússia $(0,5 / 8)$, colocada em perspectiva unicamente por alguns números eloqüentes (número de embaixadas, de pessoal), enquanto é bem desenvolvida em outros lugares graças a numerosos artigos temáticos.

Por outro lado, a idéia claramente afirmada é a de continuidade da política externa em todos os regimes (um pouco à maneira brasileira, mesmo que no Brasil as mudanças tenham sido apenas políticas), desde antes da Rússia dos Romanov até a Rússia de Putin, passando pela URSS, ou seja, da monarquia czarista até a quase democracia atual, passando pela era comunista. Muito diferente da ocultação chinesa, esta maneira de escrever ou de apresentar a história da política externa russa, apagando as mudanças dos regimes políticos, não é isolada: é um método compartilhado com italianos, brasileiros e até franceses.

Enfim, como terceira característica do site, o MID inscreve sua política em uma duração bastante longa, retomando a política externa russa desde a formação política da Rússia. A primeira parte da exposição começa no século IX (mesmo a França, tão preocupada com sua história e com a antigüidade de sua história não ousa voltar tão longe), data a que comumente se atribui o nascimento da Rússia (o MID só foi criado com este nome em 1802). A Rússia é apresentada como sendo parte vencedora depois de mais de mil anos de grandes apostas mundiais, uma Rússia sempre ativa em política exterior, presente tanto em Constantinopla como no processo de globalização atual, animadora da luta anti-fascista, partidária decisiva da Resistência...

Portugal faz de seu Ministério dos Negócios Estrangeiros um site com ilustrações bem detalhadas, no qual a história surge bem colocada (www.minnestrangeiros.pt/mne), terceira de sete entradas, mas é um pouco modesta (3 subentradas em 28). A parte “Aspectos Históricos” se decompõe em três elementos: a breve "História da Instituição" de uma meia folha (www.min-nestrangeiros.pt/ mne/historia); a "Sinopse da História Diplomática Portuguesa”, na realidade, uma 
simples lista de soberanos, sem datas, seguida de uma longa e detalhada cronologia incluindo, com datas, os ministérios das relações exteriores e os principais fatos que um diplomata achou por bem selecionar (www.min-nestrangeiros.pt/mne/ histdiplomatica/principal.html); enfim, uma série de discursos, “Discursos”, encerra o conjunto. Porém ao centralizar sua cronologia mais detalhada (36 páginas) sobre o ministério, os ministros e as relações diplomáticas, esta parte do site chega a um resultado interessante (www.min-nestrangeiros.pt/mne/histdiplomatica/sino36.html): não mencionar nenhuma mudança de regime sequer, nem mesmo o nome de Salazar até 1936, para assinalar simplesmente que ele toma provisoriamente o ministério, sem dar ao leitor a sua função principal ${ }^{9}$... Assim, o leitor não tem mais noção de mudança de regime durante os anos vinte, que na metade dos anos 70 .

O site alemão do Auswärtiges Amt é, neste ponto de vista, melhor sucedido (www.auswaertiges.amt.de). Existe logo no princípio uma entrada histórica (www.auswaertiges.amt.de/www/de/aamt/geschichte/index.html) e outra para determinados arquivos (www.auswaertiges.amt.de/www/de/infoservice/politik/ index.html). O site de história tece um histórico geral do ministério desde 1870 que não contorna, por exemplo, o assunto do nazismo. Além do mais, certas páginas tendem a sublinhar, não sem fundamento, aliás, que a diplomacia tradicional e o ministério perderam (um pouco) sua importância, seu poder e, implicitamente - o que mais importa para o site e para a imagem do ministério - sua responsabilidade, à medida em que o poder nacional-socialista conferiu competência em matéria internacional, seja ao partido nacional-socialista, seja a outros ministérios (Propaganda em particular).

O State Department norte-americano é, como o site alemão, claro e sem maiores desvios (www.state.gov). Comparado com um site do tipo do de Portugal, ele dispõe, é bem verdade, de mais meios financeiros, técnicos e científicos, mas possui, sobretudo, menos variações políticas a serem explicadas, justificadas ou esquecidas. A parte histórica (History, Education \& Culture, uma das nove entradas do site) se abre sobre o Office of the Historian. É primeiramente o domínio das fontes, das respostas às perguntas do público ou, mais particularmente, dos pesquisadores. Dependente do Bureau of Public Affairs do State Department, o site inclui em sua entrada histórica onze janelas, das quais uma cronologia detalhada das viagens presidenciais e do Secretário de Estado (www.state.gov/r/pa/ho/trvl/ c4388.htm), uma entrada especial sobre a documentação ligada ao "Holocausto", e uma cronologia da história diplomática nacional (Timeline of US Diplomatic History): na qual, em um modelo bastante comum (que se encontra também no site francês), uma galeria de fotos (www.state.gov/r/pa/ho/c1799.htm) permite visualizar, ao clicar sobre uma imagem escolhida, por amplas informações (história diplomática no site americano, biografias no site francês). No começo de março de 2002, estas informações não são completas, a não ser para o período da Independência (já que o site francês está, deste ponto de vista, terminado) 


\section{Relações exteriores: a estratégia de prioridades ou a instrumentalização da História}

Existem outros países para os quais a estratégia institucional parece ser exatamente o inverso da espanhola e argentina. Tais são os casos do Brasil e da França. Encontramo-nos frente a uma abundância de história.

O site do Ministério das Relações Exteriores do Brasil (www.itamaraty.gov.br) é um dos que mais valoriza a história nacional e, em particular, a história das relações internacionais. Uma das quinze entradas (Temas de Política Externa) conduz a um breve "Panorama da Política Externa" ou para "A construção da Nação” (http://www.mre.gov.br/cdbrasil/itamaraty/web/port/index.htm). Sobretudo, uma das três entradas apresentadas como centrais, "A Diplomacia Brasileira”, abre em quatro entradas para o histórico dominante das quais a segunda, "História da Diplomacia Brasileira” (http://www.mre.gov.br/acs/diplomacia/portg/h_diplom/ menu_hd.htm) é um livro de história completo em duas versões, português ou inglês, de cada uma das centenas de páginas (http://www.mre.gov.br/acs/ diplomacia).

Esta importância da História está sem dúvida ligada, por um lado, à existência e à antigüidade (em relação à maior parte dos países do continente) da escola diplomática, Instituto Rio Branco e, por outro lado, ao desenvolvimento, dentro do país, de uma história das relações internacionais de nível considerável. Mas tais elementos de explicação são muito fracos, mesmo se a analogia das situações entre França e Brasil contribui para validar tais hipóteses. Isto porque existem outros países dispondo de um bom nível de estudo da história das relações internacionais (Estados Unidos, Alemanha...) e de antigas escolas de formação de diplomatas (Reino Unido, Alemanha...) que fazem escolhas diferentes no momento da construção de seus sites. Sem dúvida existe uma relação com a vontade de justificar sua potência, regional pelo menos, sublinhando, aos olhos do público, o caráter antigo, refletido e historicamente "linear" da política externa nacional.

O site do Ministère des Affaires Étrangères da França (www.diplomatie. gouv.fr/index.html) é, juntamente com o do ministério brasileiro, o site consultado que contém mais história. É também, neste domínio, o site mais completo, um site consideravelmente detalhado. Em sua entrada "archives diplomatiques" (www.diplomatie.gouv.fr/archives/index.html), uma das treze entradas do site, a história surge por entre nove subentradas (também detalhadas) dentre as quais uma bela galeria de fotos comentadas (www.diplomatie.gouv/archives/dossiers/ 140ministres/index.html) e uma curta série de "Quelques grandes figures de la diplomatie” (www.diplomatie.gouv/archives/dossiers/grandes-figures/index.html) : Richelieu, Vergennes, Chateaubriand, Briand.

O site foi bastante modificado e melhorado em 2001. Um prefácio a esta entrada de arquivos (d'Hélène Carrère-d'Encausse) foi suprimido. O site conserva, 
porém, o traço profundo da síndrome de Vichy na administração dos assuntos estrangeiros. Com efeito, na galeria de retratos, iniciando em 1574 com Luis de Revol $^{10}$, uma bela continuidade, bastante artificial, permite passar praticamente da França do fim da III República à França do exílio, reunida em Londres em torno do general De Gaulle. De uma certa maneira, o leitor é levado a pensar que os assuntos estrangeiros não existiram na época de Vichy e que, consequentemente, o ministério não teve nada a ver com os “Anées Noires”. Esta simplificação máxima da memória não é exclusiva, na França, do site do ministério das relações exteriores: é a abordagem proposta tanto pela solitária e preciosa síntese da história do ministério das relações exteriores publicada pelo CNRS ${ }^{11}$ como pelo Annuaire Diplomatique, uma publicação anual dos assuntos estrangeiros (e pela Association française d'action artistique sob uma versão pouco modificada)... O do ministério propõe, portanto, em sua galeria de retratos, uma cronologia em imagem totalmente de acordo com a memória dominante em respeito - o termo não é um dos mais modernos - à Segunda Guerra Mundial: isto diz muito sobre o que não se quer compreender de Vichy. Detalhadamente, as margens de ocultação são ligeiramente flutuantes, a Terceira República tendo sido, de fato, prolongada um semestre com Paul Baudoin, "ministro do governo de Vichy"12 mas ao mesmo tempo, "ministro da Terceira República”"13.

E a contradição interna não incomoda. Se Laval está ausente da galeria de retratos como ministro de relações exteriores durante a Segunda Guerra Mundial, ele aparece, todavia, na entrada consagrada ao entreguerras, tendo de fato ocupado esta pasta cinco vezes entre 1932 e 1936; e quando clicamos sobre este retrato de Laval, o texto o faz reaparecer como ministro durante a Ocupação, mas somente de abril de 1942 a agosto de 1944, não de outubro de 1940 a dezembro de 1941, como se o início do Estado francês (é em parte verdade que ele é incluído neste site na Terceira República), apesar de tão fundador da colaboração e da política de exclusão, deveria ser isentado de Laval ${ }^{14}$ ! Assim, ao menos quanto à Segunda Guerra Mundial, a confusão entre memória e história, segundo estereótipos “científicos” comuns, é patente na representação dada pelo site da política externa da França. Uma confusão deliberada, já que a decisão agravante é tomada quando da construção do site, qual seja, a de não levar em consideração as objeções científicas de certos membros da comissão encarregados de sua elaboração.

Através dos quatorze sites estudados, observamos, portanto, as estratégias variadas de apresentação da História, às vezes utilizada de maneira complementar.

Há, freqüentemente, a História como dificuldade não superada, com os sites nos quais a História coloca em evidência um certo número de problemas (Bélgica). As respostas ou desvios variam: da amnésia total (Argentina e Espanha) ou parcial (Japão e China), do resumo um pouco superficial para certos períodos (Bélgica) a um "polimento" político ou uma reconstrução bastante simplificada (Portugal) até, por vezes pontualmente acrobática e contraditória (França) - a 
atualidade política francesa evidenciando a inconseqüência deste uso deliberado da História.

Há também a História como manifestação de antigüidade, até mesmo de anterioridade: os sites onde a História deve mostrar a antigüidade, ou até a anterioridade da potência regional (Rússia e França, principalmente).

Por fim, a História como afirmação ou memória da grandeza nacional, sensível por meio dos sites que manifestam implicitamente, via uma história excessiva, esta aspiração à grandeza nacional (Brasil e França).

Este exame deve ser continuado. Deve-se estudar, em detalhes e com uma equipe de especialistas de cada zona geográfica, muitos outros aspectos destes sites: sua gênese e, em particular, se foi escrita por diplomatas ou por historiadores, da instituição ou não; a administração das mudanças de regime político; a construção, instrumentalização ou desaparição, por vezes, de heróis da história nacional; a presença do estrangeiro nestas histórias...

\section{Notas}

1 Este trabalho é resultado de pesquisas na Internet feitas durante o $2^{\circ}$. semestre de 2001 e reflete, portanto, apenas a situação dos sites a essa data.

2 Em função basicamente da falta de informação sobre os motivos prévios que levaram à construção de sites, toda tentativa de explicação neste artigo não podem ir além de conjunturas.

3 Este trabalho foi preparado entre junho de 2001 e fevereiro de 2002. Ele reflete uma consulta aos sites, em sua maior parte na passagem 2001-2002, e não leva em conta as modificações posteriores. Ora, certos sites recebem acréscimos (México), outros são amplamente revisados (França).

“Aviso aos navegantes; Bolsas, subvenções e leitores; Resumos da imprensa quotidiana; Informações gerais; Entrar no MAE; Embaixadas e consulados; Novidades; O OID informa; Conferências e publicações; Concursos; Links; Órgãos vinculados; Informações sobre os funcionários do MAE”.

5 “A Chancelaria, Serviço ao viajante, Comércio exterior, A República Argentina”.

6 “A parceria duradoura, estável e construtiva entre a China e a União Européia.

7 "Estabelecimento das relações diplomáticas sino-francesas”.

8 Em 1991, foi decidido denominá-lo Ministério das Relações Exteriores. Mas este artigo ainda é assinado em dezembro de 2001 como departamento do MID. Em todos os lugares menciona-se MID.

$9 \quad$ O nome aparece em seguida em 1942, 1943, 1957.

10 Mas em 1589 no título.

11 Les Affaires étrangères et le corps diplomatique français, tomo II, Paris, CNRS, 1984.

12 O tratamento da Segunda Guerra Mundial por este site parece ter dado lugar a amplos debates internos no ministério, mas a tradição negando qualquer limite entre a III República e a França livre levou a melhor.

13 Além do mais, ele se demite após Montoire, Laval assume os Assuntos Estrangeiros; depois disso, ele não passa de ministro secretário de Estado da Presidência do Conselho (Jean-Baptiste Duroselle, L’Abîme 1939-1944, Imprimerie Nationale, 1986, p. 269).

14 "LAVAL (Pierre), senador, presidente do Conselho, falecido em 15 de outubro de 1945. 14 de janeiro - 21 de fevereiro de 1932 ; 13 de outubro - 7 de junho de 1935, três vezes ministro; 7 de 
junho de 1935 - 24 de janeiro de 1936, senador, presidente do Conselho, ministro pela quinta vez. 18 de abril de 1942 - agosto de 1944, ministro do Governo de Vichy” www.diplomatie.gouv.fr/archives/archives/expo/140/2guer/08.html.

\section{Resumo}

A Internet é aqui considerada uma fonte alternativa do estudo da história, sobretudo história das relações diplomáticas. São analisados os sites dos ministérios das relações exteriores pelo mundo: alguns atribuem grande importância à história, com detalhada visão retrospectiva (Brasil, França, México, Rússia, Alemanha, Estados Unidos), outros têm abordagem seletiva ou restrita a determinados períodos (Espanha, Argentina, Itália, Bélgica, Portugal, China, Japão), uns se voltam para o passado, somente com informações históricas que sejam indispensáveis à imagem nacional (Suíça) e outros mostram sua história voltada para o futuro (Grã-Bretanha).

\section{Abstract}

Internet is considered an alternative source to study the history, mainly the history of diplomatic relations. The sites of the ministries of external relations around the world are analized: some attribute great importance to the history, with detailed retrospective analysis (Brazil, France, Mexico, Russia, Germany, United States); others do a selective analysis, or restricted to certain periods (Spain, Argentina, Italy, Belgium, Portugal, China, Japan); some emphasize the past, only showing historical information that are indispensable to the national image (Switzerland); and others show their history turned to the future (Britain).

Palavras-chave: Internet; História; Sites dos Ministérios das Relações Exteriores. Key words: Internet; History; Web sites of the Ministries of Foreign Affairs. 